\title{
CSP Algorithm In Predicting And Optimizing The Path Loss Of Wireless Empirical Propagation Models
}

\author{
Nagendra sah and Amit Kumar
}

\begin{abstract}
Constraint satisfaction programming (CSP) is an emergent software technology for declarative description and effective solving of large particularly combinational problem especially in term of planning and scheduling. Constraint programming is the study of computational system based on constraints. The idea of constraint programming is to solve problem by stating constraints about the problem and consequently finding the solution satisfying all the constraints. In this paper the application of constraint satisfaction programming is used in predicting the path loss of various empirical propagation models using chronological backtrack algorithm, which is basic algorithm of CSP. After predicting the path loss at different set of parameter such as frequencies, height of base station antenna, range of cell etc, we find the optimum set of parameter (frequency (f), base station height $(\mathrm{hb})$, mobile antenna height $(\mathrm{hm})$, cell $\mathrm{radius}(\mathrm{r} / \mathrm{d})$ at which path loss is minimum with the help of Branch and bound algorithms used to optimized the constraint satisfaction problems.
\end{abstract}

Index Terms-Path loss, prediction models constraint satisfaction programming, CSP Algorithms, Mobile Communication, Propagation, LOS and NLOS Conditions.

\section{INTRODUCTION}

In last few years, the constraint satisfaction programming (CSP) has attracted high attention among experts from many years because of its potential for solving problems. The constraint satisfaction programming approach has been widely used in many academics and research parlance to tackle wide range of search problem. It is defined by finite set of variables, a set of domain and constraints. Basically CSP composed of finite set of variable, each of which is associated with a set of domain, and set of constraints that restrict the value that variable can take. The constraints satisfaction problem deal with the assignment of values from its domain to the variable in such a way that no constraint is violated [1]. There are currently two branches of constraint programming, namely constraint satisfaction and constraint solving. Constraint satisfaction deals with the problem defined over finite domain and currently, probably more than $95 \%$ of all industrial constraint applications used finite domains, on the other hand constraint solving algorithm are based on mathematical techniques. The CSP is worth studying in

Manuscript received May 5, 2009. Final version of paper is resubmitted June, 2009.

F. A. Prof.Nagendra Sah is with PEC University of Technology, Sector-12, Chandigarh, PIN-160012, India.

Phone No. +911722749601 , Mobile No. $=919872560513$

S. A. Amit Kumar is pursuing his master of Engg. Degree with PEC University of Technology, Sector-12, Chandigarh, PIN-160012, India. isolation because it has a unique feature that can be exploited to arrive at solution. The constraint satisfaction programming (CSP) offers its basic algorithm to solve and optimize the problem.

Constraints satisfaction algorithm can be viewed as an iterative procedure that repeatedly assigns domain value to the variables [2].

In this paper problem of finding the path loss of various Empirical wireless propagation models has been stated as a CSP (constraint satisfaction problem) and has been solved by chronological backtracking algorithm. The result is optimized using constraint satisfaction optimizing algorithm such as branch and bound algorithm which is the very basic algorithm.

In section II, the importance and usefulness of propagation models are discussed. In section III, methodology of CSP and optimization algorithm are fully described. The analysis of the empirical propagation models is done and resulte are shown in section IV.

\section{Propagation Models}

The prediction model plays an important role in designing cellular mobile radio communication system. Propagation models are used extensively in network planning, particularly for conducting feasibility studies and during initial deployment. These are also very important for performing interference studies as the deployment proceeds. Propagation loss modeling of cellular mobile system is important for site planning; the transmission loss and signal coverage can be predicted by set of propagation loss modeling equations [4].

Propagation models in wireless communication have traditionally focused on predicting the average received signal strength at a given distance from the transmitter as well as the variability of the signal strength in close proximity to a particular location. Propagation models that predict the mean signal strength for an arbitrary transmitter - receiver separation distance are useful in estimating the radio coverage area of transmitter and are called large scale propagation models, since they characterize signal strength over large T-R separation distance.

On the other hand, propagation model that characterize the rapid fluctuation of the received signal strength over very short travel distances or short time duration are called small scale or fading models. As mobile moves over very small distances, the instantaneous received signal strength may fluctuate rapidly giving rise to small scale fading. The reason for this is that received signal is sum of many contributions coming from different directions [5]. 
The propagation models are generally used to characterize the quality of mobile communication. It can be used as prediction tool for those telecommunication engineers who deal with the site planning for base station. These models can be broadly categorized into three types: empirical, deterministic and stochastic. Empirical models are based on observation and measurement alone. These are mainly used to predict path loss. The deterministic models make use of the laws governing electromagnetic wave propagation to determine the received signal power at a particular location. Stochastic model, on other hand model the environment and use much less processing power to generate prediction [4]. The concept of constraint satisfaction programming has been implemented on empirical wireless propagation models in order to predicting and optimizing the propagation loss [6].

\section{Methodology Of CSP}

The two algorithms of CSP, chronological backtracking and branch and bound which are used to solve and optimize the wireless empirical propagation models may be explained as below:- The basic operation of chronological backtrack algorithm in CSP context is to find the solution tuples. This algorithm took one variable at a time, and consider one value for it at a time, making sure that newly picked variable is compatible with the all the labels picked so far. Assigning a value to variable is called labelling. If labelling the current variable with the picked value violates certain constraints, then next value is assigned to the variable. If all the variables are labelled, then the problem is solved [3]. The flow diagram of the chronological backtracks algorithm may be shown as below:-

Flow Diagram Of Chronological Backtrack Algorithm:-

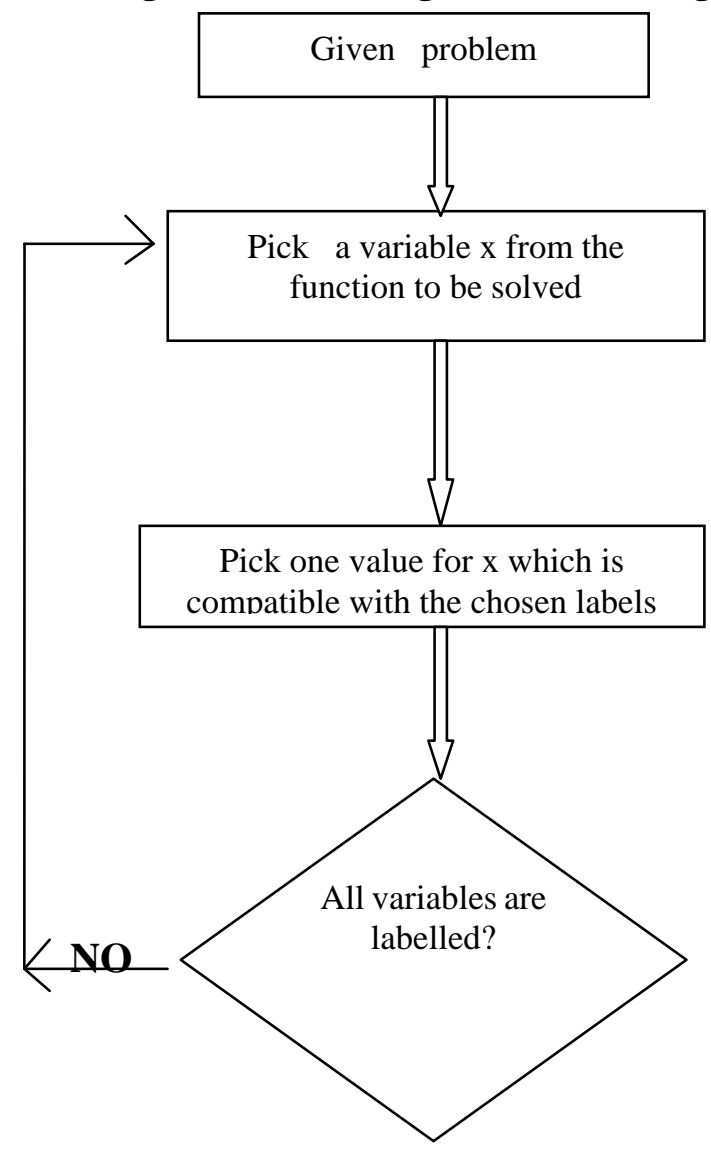

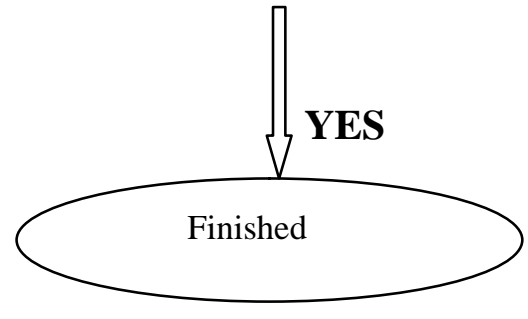

Figure (1)

The low diagram explain the working of backtrack algorithm. As its name indicate that it will backtrack until and unless all the variables are labelled, and in last when all the variables are labelled the problem get solved. In context with the wireless empirical propagation model, we have different types of variables, such as base station antenna height ( $\mathrm{hb}$ ), frequency(f), range of cell $(\mathrm{d} / \mathrm{r})$, the height of the mobile station antenna height $(\mathrm{hm})$ etc. Each variable is treated as domain for these set of variables by stating the constraints that value of variables should not go beyond the specified domain i.e it should not violate the constraints. After implementation of the backtrack algorithm, we find the path loss of empirical propagation model at different set Frequency(f), base station antenna height (hb), cell $\operatorname{radius}(\mathrm{d} / \mathrm{r})$, and mobile antenna height $(\mathrm{hm})$. Now after finding the path loss for different set of parameters (f, hb; d\r, $\mathrm{hm}$ ), we have to find that particular set of parameter at which propagation loss is minimum. For this optimization CSP provides an optimization algorithm called branch and bound algorithm which may be explained as below:-

\section{A. Branch And Bound Algorithm}

Branch and bound is a general search algorithm for finding optimal solution, make use of knowledge on the $f$ value. A constraint satisfaction optimization problem (CSOP) is defined as CSP, together with an optimization function $f$ which maps every solution tuple to a numerical value. So constraint satisfaction optimization problem is written as: $(\mathrm{Z}$, $\mathrm{D}, \mathrm{C}, \mathrm{f})$ where $(\mathrm{Z}, \mathrm{D}, \mathrm{C})$ represent CSP with a set of variables $(\mathrm{Z})$, domain (D) and constraints(C) and $\mathrm{f}$ is the optimization function. To apply the branch and bound algorithm to CSOP one needs to have knowledge of heuristic function which maps every compound label to numerical value. A bound is nothing but a global variable which is defined according to the minimization or maximization problem, it depends upon the case that either you want minimum or maximum value of the function you are solving[3]. The branch and bound algorithm in empirical wireless propagation models is used to find that particular set of frequency(f), base station antenna height(hb), the range of cell(d\r), and mobile antenna height $(\mathrm{hm})$ at which propagation loss is minimum. The propagation loss of different type of empirical model can be predicted by set of propagation loss modelling equations which are different for each empirical propagation model. The propagation loss modelling equation consist of different variables, in branch and bound algorithm a heuristic function is needed to assign the value to these variables. After all the variables are labelled the calculated value of path loss is taken as the $\mathrm{f}$ value in branch and bound algorithm. This $\mathrm{f}$ value in branch and bound algorithm is compared with the estimated value of the global variable (bound), and if this 
computed $f$ value is less than the value of the existing bound, it will become the new bound. This procedure will carry on until and unless a minimum value is found and reverse of this procedure is used if we have to find the maximum value.

\section{Analysis Of The EMPIRICAl Propagation Models}

The following wireless empirical propagation models has been implemented with the constraint satisfaction programming:-

$\begin{array}{ll}\ddot{y} & \text { Okumara-Hata propagation model } \\ \ddot{y} & \text { PCS- Extension to Hata model } \\ \ddot{y} & \text { Cost-231 Walfisch Ikegami model } \\ \ddot{y} & \text { Egli propagation model } \\ \ddot{y} & \text { Stanford University Interim Model (SUI } \\ & \text { MODEL) } \\ \ddot{y} & \text { Walfisch and Bertoni model }\end{array}$

\section{A. Stanford University Interim Model (SUI MODEL)}

Let us analyse the empirical propagation model by taking example of Standford University interim (SUI) model. SUI model is an extension of the Hata model with the correction parameter for frequencies above $1900 \mathrm{MHz}$. The constraints for the model were that it can be used for the base station antenna height from $10 \mathrm{~m}$ to $80 \mathrm{~m}$, the receiving antenna height between $2 \mathrm{~m}$ and $10 \mathrm{~m}$ and cell radius between $0.1 \mathrm{~km}$ to $8 \mathrm{~km}$. The basic expression for path loss calculation according to the SUI model is written as below:-

$P L=A+10 \gamma \log _{10}\left(d / d_{0}\right)+X_{f}+X_{h}+s$ for $d>d_{0}$,

where $d$ is the distance between the base station and the receiving antenna, $\mathrm{Xf}$ is a correction factor for frequency, $\mathrm{Xh}$ is the correction factor for receiver antenna height, and $\mathrm{s}$ is a correction for shadowing because of tree and clutter on a propagation path[7]. The parameter $\mathrm{A}$ is defined as follows-

$\mathrm{A}=20 \log 10(4 \pi \mathrm{d} 0 / \lambda)$

Where, $\lambda$ is the wavelength in meter. The path loss exponent $\gamma$ is given as:-

$\gamma=\mathrm{a}-\mathrm{bh} \mathrm{h}_{\mathrm{b}}+\mathrm{c} / \mathrm{h}_{\mathrm{b}}$, where $\mathrm{h}_{\mathrm{b}}$ is the base station height in meters, and $\mathrm{a}, \mathrm{b}, \mathrm{c}$ are the constant depending upon the terrain type as given in the table:-

\begin{tabular}{|l|l|l|l|}
\multicolumn{5}{|c}{ Table- (I) } \\
\hline $\begin{array}{l}\text { Model } \\
\text { parameter }\end{array}$ & $\begin{array}{l}\text { Terrain } \\
\text { A }\end{array}$ & $\begin{array}{c}\text { Terrain } \\
\text { B }\end{array}$ & $\begin{array}{c}\text { Terrain } \\
\text { C }\end{array}$ \\
\hline a & 4.6 & 4.0 & 3.6 \\
\hline b & .0075 & .0065 & .005 \\
\hline c & 12.6 & 17.1 & 20 \\
\hline
\end{tabular}

The correction factors for the frequency and receiving antenna height are written as below:-

$\mathrm{X}_{\mathrm{f}}=6.0 \log (\mathrm{f} / 2000)$ for terrain A, B, C.

$X_{h}=-10.8 \log \left(h_{r} / 2000\right)$ for terrain A\& B

$X_{h}=-20.0 \log \left(h_{r} / 2000\right)$ for terrain type $c$

Where $\mathrm{f}$ is the frequency in $\mathrm{MHz}$ and $\mathrm{h}_{\mathrm{r}}$ is the receiver antenna height in meter. These propagation loss modeling equations of SUI model were solved using the methodology of CSP at different values of frequency, base station height, distance between transmitter and receiver (d) and receiver antenna height $\left(\mathrm{h}_{\mathrm{r}}\right)$. Now after finding path loss using CSP the analysis of SUI model may be shown graphically as below:-

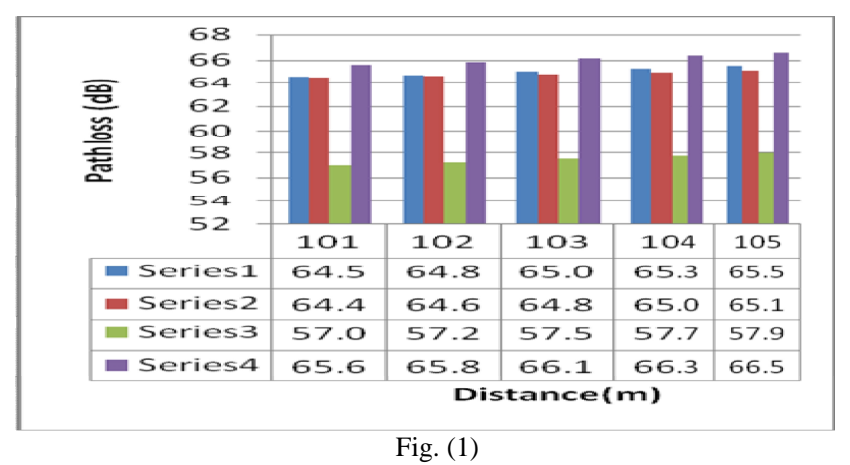

For series 1:-

\begin{tabular}{|c|c|c|c|}
\hline $\mathrm{f}(\mathrm{MHz})$ & $\mathrm{d}(\mathrm{m})$ & hte(m) & $\operatorname{hr}(\mathrm{m})$ \\
\hline 2000 & $101-105$ & 10 & 2 \\
\hline \multicolumn{4}{|c|}{ For series 2:- } \\
\hline $\mathrm{f}(\mathrm{MHz})$ & $\mathrm{d}(\mathrm{m})$ & hte(m) & $\mathrm{hr}(\mathrm{m})$ \\
\hline 2000 & $101-105$ & 80 & 2 \\
\hline \multicolumn{4}{|c|}{ For series 3:- } \\
\hline $\mathrm{f}(\mathrm{MHz})$ & $\mathrm{d}(\mathrm{m})$ & hte(m) & $\mathrm{hr}(\mathrm{m})$ \\
\hline 2000 & $101-105$ & 10 & 10 \\
\hline \multicolumn{4}{|c|}{ For series 4:- } \\
\hline $\mathrm{f}(\mathrm{MHz})$ & $\mathrm{d}(\mathrm{m})$ & hte(m) & $\mathrm{hr}(\mathrm{m})$ \\
\hline 3000 & $101-105$ & 10 & 2 \\
\hline
\end{tabular}

From the figure- 1 it can be concluded that the path loss is more at $\mathrm{hb}=10 \mathrm{~m}$, and it get decreased as the hb is increased i.e at $\mathrm{hb}=80 \mathrm{~m}$. For series 3 when value of $\mathrm{hr}$ is increased to $10 \mathrm{~m}$ the propagation loss is getting slowdown as shown in the diagram. When frequency is increased (series 4) to $3000 \mathrm{MHz}$, the path loss also increases as shown in figure-1.

SUI model is an extension of the hata model with the correction parameter for frequencies above $1900 \mathrm{MHz}$.

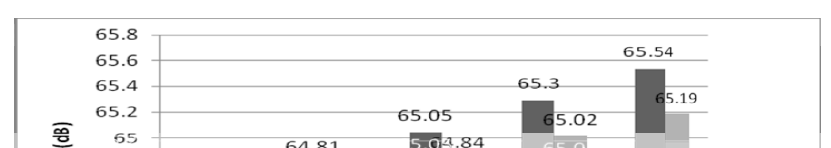

\section{L \\ Fig.2 Analysis for change in base station antenna height}

For series 1:-

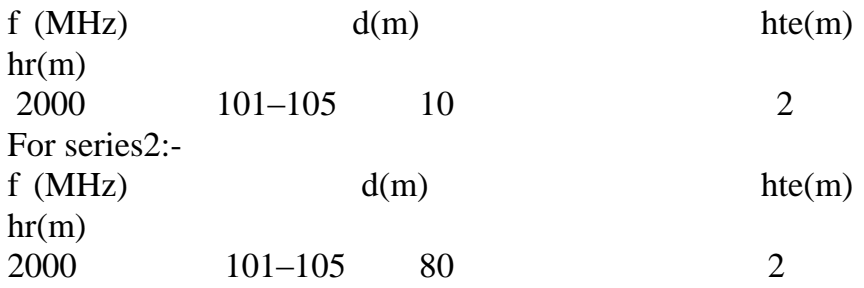

From the graphical analysis of figure-2, it is clear that when in series 2 the value of base station antenna is increased from 10 to 80 the propagation loss get fall as clear from the figure.

Now let us see the effect of increasing the height of mobile station antenna height:- 
Fig.3 Analysis change in mobile antenna height

For series 1:-

$\begin{array}{llll}\mathrm{f}(\mathrm{MHz}) & \mathrm{d}(\mathrm{m}) & \mathrm{hte}(\mathrm{m}) & \mathrm{hr}(\mathrm{m}) \\ 2000 & 101-105 & 10 & 2\end{array}$

For series 2:-

$\begin{array}{lll}\mathrm{f}(\mathrm{MHz}) & \mathrm{d}(\mathrm{m}) & \text { hte }(\mathrm{m}) \\ 2000 & 101-105 & 10\end{array}$

$\operatorname{hr}(\mathrm{m})$

$2000 \quad 101-105 \quad 10 \quad 10$

The graphical analysis of the figure- 3 shows that there is decrement in the path loss as we go on increasing the mobile antenna height in SUI model.

The following figure- 4 shows the effect of increase in frequency on path loss in SUI (standford university interim) model:-

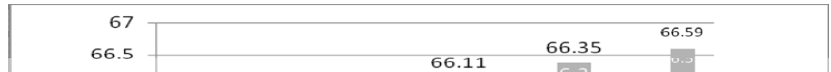

1

Fig.4 Analysis for change in value of frequency

For series 1:-

\begin{tabular}{lccc} 
f $(\mathrm{MHz})$ & \multicolumn{2}{c}{$\mathrm{d}(\mathrm{m})$} & $\mathrm{hte}(\mathrm{m})$ \\
$\mathrm{hr}(\mathrm{m})$ & & & \\
2000 & $101-105$ & 10 & \\
$\begin{array}{l}\text { For series 2:- } \\
\mathrm{f}(\mathrm{MHz})\end{array}$ & & $\mathrm{d}(\mathrm{m})$ & \\
$\mathrm{hr}(\mathrm{m})$ & & & $\mathrm{hte}(\mathrm{m})$ \\
3000 & $101-105$ & 10 & 2
\end{tabular}

It may be seen from the above figure that when the frequency get change from 2000to 3000 the propagation loss increases.

\section{B. Okumara-Hata Model}

Propagation Loss for Urban Area

The following graphical analysis of figure-5 shows the propagation loss calculation for Okumara- Hata model in case of urban area and small city with the following parameter:-

$\mathrm{f}=150 \mathrm{MHz}, \quad \mathrm{Hr}=1 \mathrm{~m}, \quad \mathrm{Hb}=30 \mathrm{~m}, \quad \mathrm{~d}=1-5 \mathrm{~km} \quad($ For series 1)

$\mathrm{f}=150 \mathrm{MHz}, \quad \mathrm{Hr}=1 \mathrm{~m}, \quad \mathrm{Hb}=100 \mathrm{~m}, \quad \mathrm{~d}=1-5 \mathrm{~km} \quad$ (For series 2)

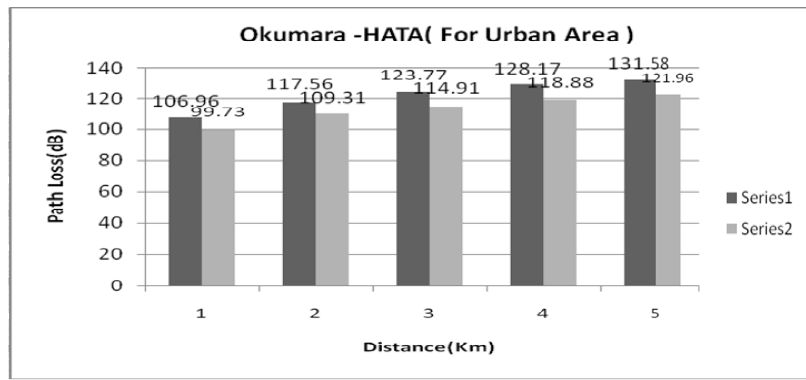

Fig.5Analysis for change in base station antenna height

It is also clear from the figure- 5 that when height of base station is increases $(\mathrm{Hb})$ the propagation loss decreases.

\section{Propagation Loss for Rural Area}

Now the following figure- 6 shows the variation of path loss for rural area for the same parameter as for urban area:-

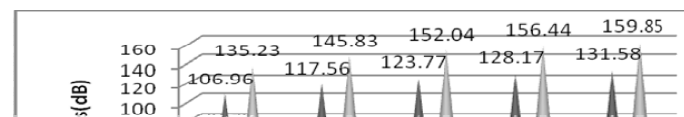

Fig.6 Analysis change in mobile antenna height

From the above figure- 6 , one can easily conclude that the path loss calculation in case of rural area is higher as compare to urban area for the same parameter (frequency (f), base station height (hb), mobile station height (hr).

\section{Propagation Loss for Suburban Area}

Let us calculate path loss in case of suburban area keeping the variable (f, hb, hr, d) same as for urban and rural.

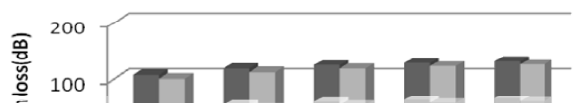

Fig.7 Analysis for Suburban area

The path loss calculation for suburban area shows that at same parameter the propagation loss is minimum. This is shown in figure-7.

Now let us see what happened when we go on increasing the height of mobile station (hr), we will calculate path loss for $\mathrm{hr}$ $=5 \mathrm{~m}$.

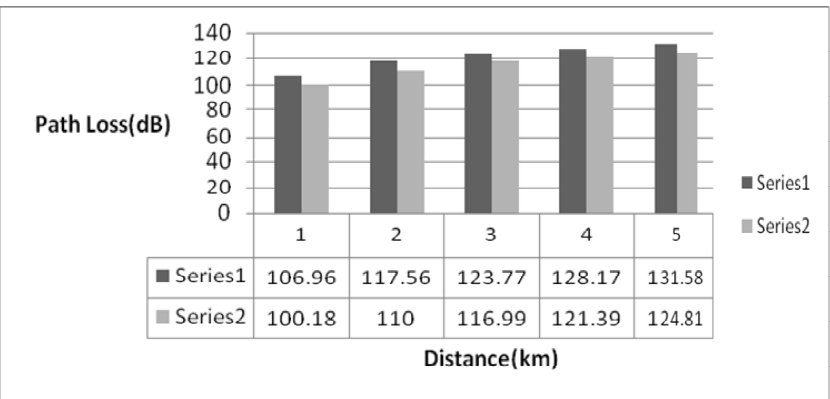


Fig 8 Analysis for increase in mobile antenna height.

It may be noted from figure- 8 that for series $1 \mathrm{hr}=1 \mathrm{~m}$, and for series 2 the value of $\mathrm{hr}=5 \mathrm{~m}$. The path loss calculation is less when $\mathrm{hr}=5 \mathrm{~m}$ i.e. the path loss decreases with the increase in mobile antenna height.

Let us increase the value of frequency now, we will calculate loss at $\mathrm{f}=200 \mathrm{MHz}$.

The $\mathrm{f}=150 \mathrm{MHz}$ for series $1 \& \mathrm{f}=200 \mathrm{MHz}$ for series 2 .

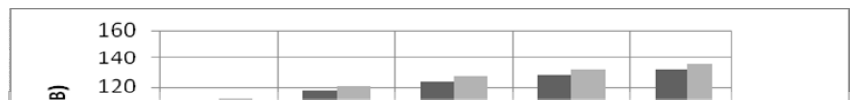

Fig.9 Analysis for increase in the value of frequency

It is clear from the above figure-9 that propagation loss increases with increase in frequency.

From the above discussion it is clear that:-

1) The propagation loss increases with the increase in distance.

2) The propagation path loss decreases as we go on increasing the height of base station antenna

3) The path loss decreases with the increase in height of mobile antenna

4) The path loss increases with increases in frequency.

\section{PCS Extention to Okumara-Hata Model}

There was a limitation of the okumara -hata model was that it was limited to the frequency range of $150 \mathrm{MHz}$ to $1500 \mathrm{MHz}$. In PCS extention the frequency range of okumara -hata was extended upto $2 \mathrm{MHz}$. The effect of increase in base station antenna height on the propagation loss may be shown as below:-

Propagation Loss for Urban Area

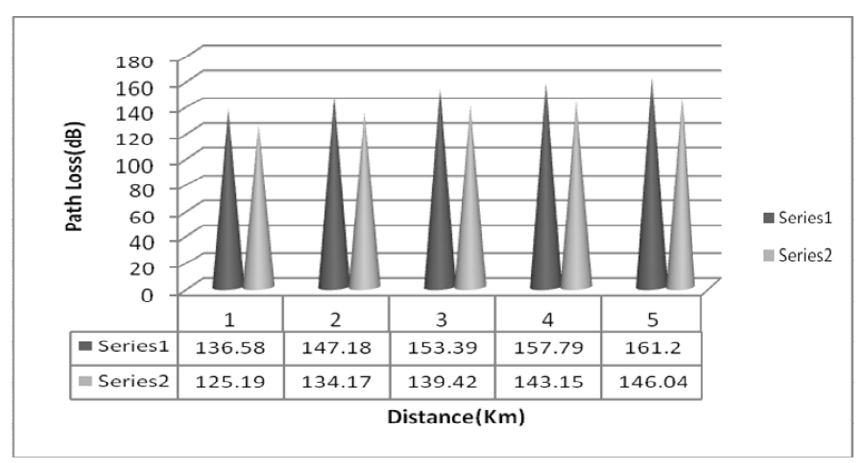

For series 1:-

Fig.10 Analysis for increased base station height

\begin{tabular}{lll}
$\mathrm{f}(\mathrm{MHz})$ & \multicolumn{2}{c}{$\mathrm{d}(\mathrm{Km})$} \\
$\mathrm{hr}(\mathrm{m})$ & & \\
1500 & $1-5$ & 30
\end{tabular}

For series2:-

$\mathrm{f}(\mathrm{MHz}) \quad \mathrm{d}(\mathrm{Km})$

$\operatorname{hr}(\mathrm{m})$

1500

$1-5$

200

hte $(\mathrm{m})$

1

hte $(\mathrm{m})$

1

From series 1 it is very much clear that path loss is less at $\mathrm{d}$
$=1$, and more at $\mathrm{d}=5$. From series 2 when base station height is increased from $30 \mathrm{~m}$ to $200 \mathrm{~m}$ path loss goes on decreasing. This is shown in figure-10.

Let us examine the influence of the receiver antenna height on path loss:-

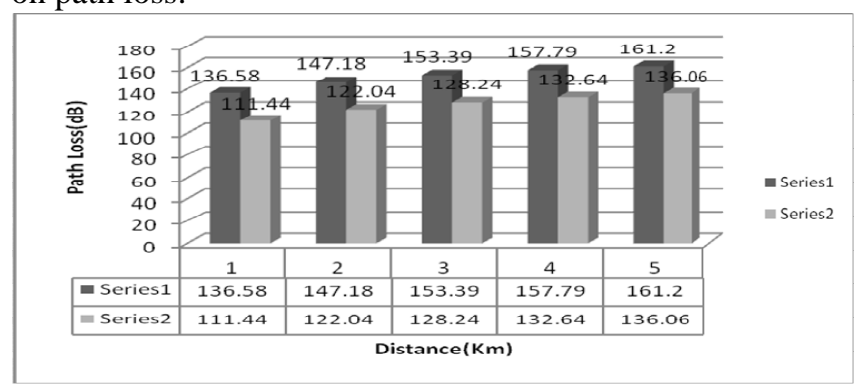

Fig.11 Analysis for increased mobile antenna height

For series1:-

$\begin{array}{llccc}\mathrm{f}(\mathrm{MHz}) & \mathrm{d}(\mathrm{Km}) & \mathrm{hte}(\mathrm{m}) & & \mathrm{hr}(\mathrm{m}) \\ 1500 & 1-5 & 30 & 1 & \\ \begin{array}{l}\text { For series2:- } \\ \mathrm{f}(\mathrm{MHz})\end{array} & \mathrm{d}(\mathrm{Km}) & & & \mathrm{hte}(\mathrm{m}) \\ 1500 & 1-5 & 30 & 10 & \mathrm{hr}(\mathrm{m})\end{array}$

In series 2 when height of mobile antenna $(\mathrm{hr}=10 \mathrm{~m})$ is increased loss is decreasing. This is shown in figure- 11 .

When we increase the values of frequency the propagation loss will show behaviour as shown in the following figure- 12 .

$$
=200
$$

For series 1:

Fig.12 Analysis for increased in frequency range

$\mathrm{f}(\mathrm{MHz}) \quad \mathrm{d}(\mathrm{Km}) \quad$ hte $(\mathrm{m})$

$\mathrm{hr}(\mathrm{m})$

$1500 \quad 1-5 \quad 30$

For series2:-

$\mathrm{f}(\mathrm{MHz}) \quad \mathrm{d}(\mathrm{Km}) \quad$ hte $(\mathrm{m})$

$\mathrm{hr}(\mathrm{m})$

2000

$1-5$

30

1

From the above graphical analysis it shows that the propagation loss gets increased with the increase in the frequency range.

Propagation Loss for Suburban Area

Let us calculate path loss in case of suburban area keeping the variable (f, hb, hr, d) same as for urban area.

For series 1:-

$\mathrm{f}(\mathrm{MHz}) \quad \mathrm{d}(\mathrm{Km}) \quad$ hte $(\mathrm{m})$ $\mathrm{hr}(\mathrm{m})$

For series2:-

$\mathrm{f}(\mathrm{MHz}) \quad \mathrm{d}(\mathrm{Km})$

$\operatorname{hr}(\mathrm{m})$

$1500 \quad 1-5 \quad 200$

hte(m)

1 


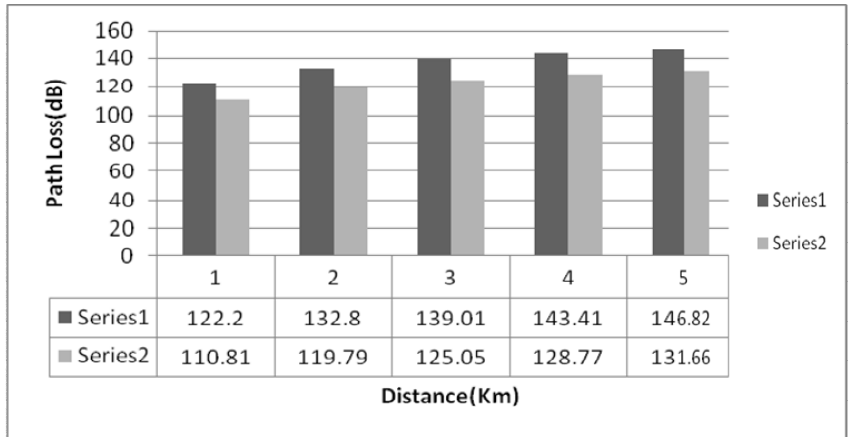

Fig.13 Analysis for increased base station height

The path loss calculation for suburban area shows the same behaviour i.e. the path loss increases with increase in distance and decreases with the height of base station height. This is shown in figure-13.

Now let us see what happen when the height of the mobile station antenna is increased from 1 to $10 \mathrm{~m}$.

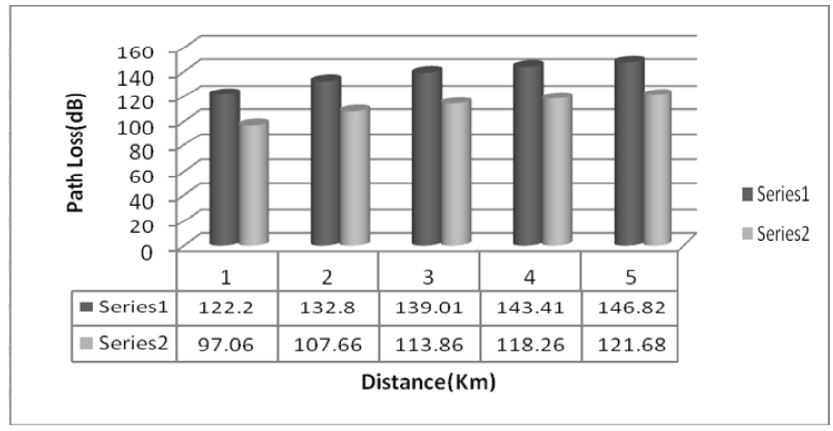

For series 1:-

Fig.14 Analysis for increased receiver antenna height

$\begin{array}{lcccc}\mathrm{f}(\mathrm{MHz}) & & \mathrm{d}(\mathrm{Km}) & \mathrm{hte}(\mathrm{m}) \\ \mathrm{hr}(\mathrm{m}) & & & & \\ 1500 & 1-5 & & 30 & \\ \begin{array}{l}\text { For series2:- } \\ \mathrm{f}(\mathrm{MHz})\end{array} & & \mathrm{d}(\mathrm{Km}) & & \mathrm{hte}(\mathrm{m}) \\ \mathrm{hr}(\mathrm{m}) & & & & \\ 1500 & 1-5 & 200 & 10 & \end{array}$

From the above graphical analysis of figure-14, it is clear that the propagation loss is getting decrease with increase in the height of receiver.

The effect of increase in frequency for suburban area may be examined as shown below in figure- 15 .

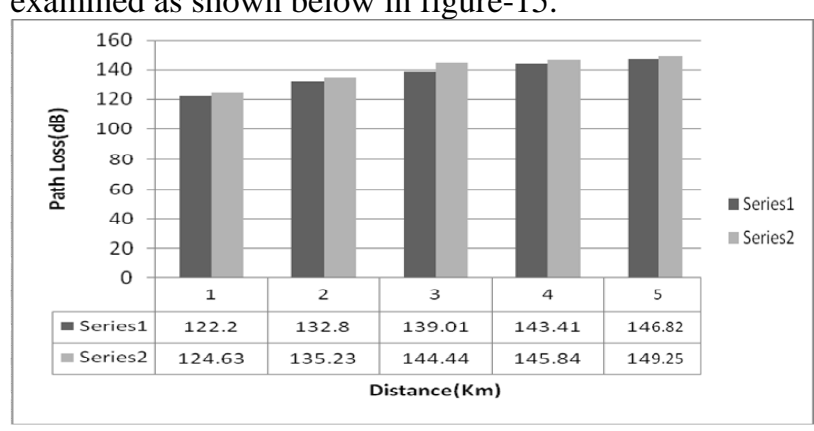

Fig.15 Analysis for increased frequency

For series 1:-

$\mathrm{f}(\mathrm{MHz})$
$\mathrm{hr}(\mathrm{m})$

$1500 \quad 1-5 \quad 30$

For series2:- f $(\mathrm{MHz})$

$\mathrm{hr}(\mathrm{m})$

2000

$1-5$

$\mathrm{d}(\mathrm{Km})$

hte $(\mathrm{m})$

From the above discussion it is clear that the propagation loss in case of suburban area is less in magnitude as compare to the urban area, but gives same response with the change in frequency.

\section{Propagation Loss for Rural Area}

The path loss calculation for PCS- Extension to Hata model in rural area may be analysed graphically as below:-

Fig.16 Analysis for increased base station height

For series 1:-

f $(\mathrm{MHz})$

$\mathrm{d}(\mathrm{Km})$

hte(m)

$\mathrm{hr}(\mathrm{m})$

1500

$1-5$

30

1

For series 2:-

f $(\mathrm{MHz})$

$\mathrm{hr}(\mathrm{m})$

1500

$\mathrm{d}(\mathrm{Km})$

$1-5$

200

hte $(\mathrm{m})$

The propagation loss calculation for rural area in case of PCS-Extension to Okumara-Hata model show that at the same parameters of frequency, base station antenna height, receiver antenna height and distance between transmitter and receiver is higher as compare to Urban and suburban area. The path loss is getting increased with distance and decreases with base station height as in case of urban and suburban area. This is shown in figure-16.

The change in magnitude of path loss with the change in receiver antenna height has been explained as below:-

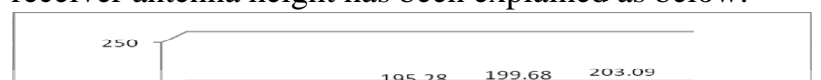

Fig.17 Analysis for increased receiver antenna height

For series 1:-

$\mathrm{f}(\mathrm{MHz}) \quad \mathrm{d}(\mathrm{Km}) \quad$ hte $(\mathrm{m})$

$\mathrm{hr}(\mathrm{m})$

$1500 \quad 1-5 \quad 30$

1 
For series2:-

f $(\mathrm{MHz})$

$\operatorname{hr}(\mathrm{m})$

$\mathrm{d}(\mathrm{Km})$

hte $(\mathrm{m})$

1500

$1-5$

30

10

It is clear from the figure-17 that when we increase the height of mobile antenna height the path loss is getting decreased.

Let us examine the effect of increased frequency on propagation loss for PCS-Extension to Hata model in rural area:-

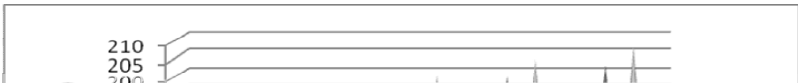

Fig.18 Analysis for increased value of frequency

For series 1:-

$\mathrm{f}(\mathrm{MHz}) \quad \mathrm{d}(\mathrm{Km})$

$\operatorname{hr}(\mathrm{m})$

$1500 \quad 1-5 \quad 30$

For series2:-

$\mathrm{d}(\mathrm{Km})$

f $(\mathrm{MHz})$

2000

$1-5$

30

hte $(\mathrm{m})$

hte(m)

The graphical analysis of figure-18 shows that the propagation loss is increasing with the increase in frequency and is more as compare to the urban and suburban area.

\section{Cost-231 Walfisch Ikegami Model}

This model allows for improved path-lss estimation by consideration of more data to describe the character of the urban environment, namely:-

- Height of building (h roof)

- Width of roads $(w)$

- Building sepration $b$ and

- Road orientation with respect to direct radio path(a)

This model allows for improved path-loss estimation by consideration of more data to describe the character of the urban environment.

$\mathrm{f}=800 \mathrm{MHz}, \mathrm{Hr}=1 \mathrm{~m}, \mathrm{Hb}=4 \mathrm{~m}, \mathrm{~d}=0.02-2.02 \mathrm{~km} \quad$ (For series 1 )

$\mathrm{f}=2000 \mathrm{MHz}, \mathrm{Hr}=1 \mathrm{~m}, \mathrm{Hb}=4 \mathrm{~m}, \mathrm{~d}=0.02-2.02 \mathrm{~km}$

(For series 2)

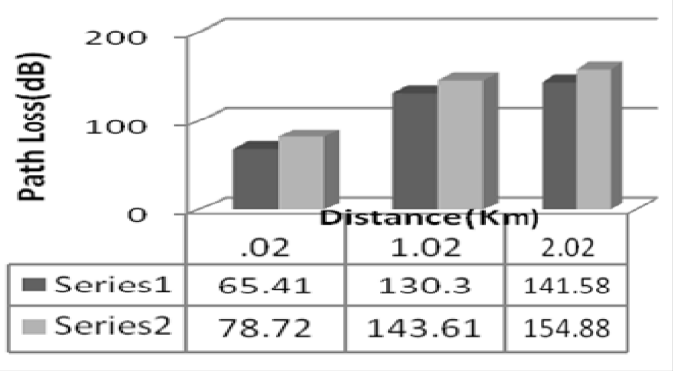

Fig. (19)
So it is very much clear from the figure-19 that at higher frequency the path loss is high as compare to the lower frequency.

$\mathrm{f}=800 \mathrm{MHz}, \mathrm{Hr}=1 \mathrm{~m}, \mathrm{Hb}=4 \mathrm{~m}, \mathrm{~d}=0.02-2.02 \mathrm{~km} \quad$ (For series 1)

$\mathrm{f}=800 \mathrm{MHz}, \mathrm{Hr}=2 \mathrm{~m}, \mathrm{Hb}=4 \mathrm{~m}, \mathrm{~d}=0.02-2.02 \mathrm{~km}$

(For series 2)

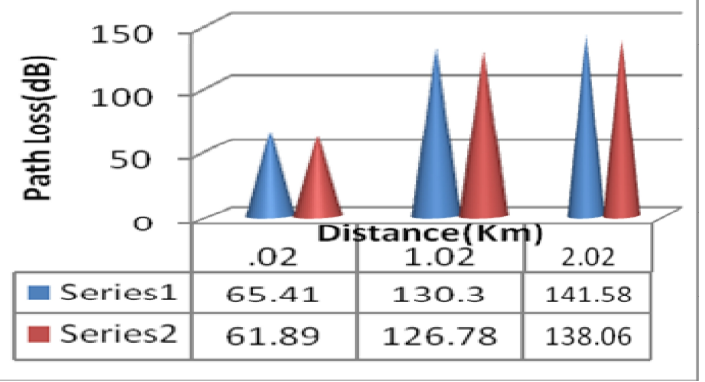

Fig. (20)

When antenna height of antenna receiver increases the propagation loss goes on decreasing as shown above figure-20.

$\mathrm{f}=800 \mathrm{MHz}, \mathrm{Hr}=1 \mathrm{~m}, \mathrm{Hb}=4 \mathrm{~m}, \mathrm{~d}=.02-2.02 \mathrm{~km} \quad$ (For series 1)

$\mathrm{f}=2000 \mathrm{MHz}, \mathrm{Hr}=1 \mathrm{~m}, \mathrm{Hb}=10 \mathrm{~m}, \mathrm{~d}=.02-2.02 \mathrm{~km}$

(For series 2)

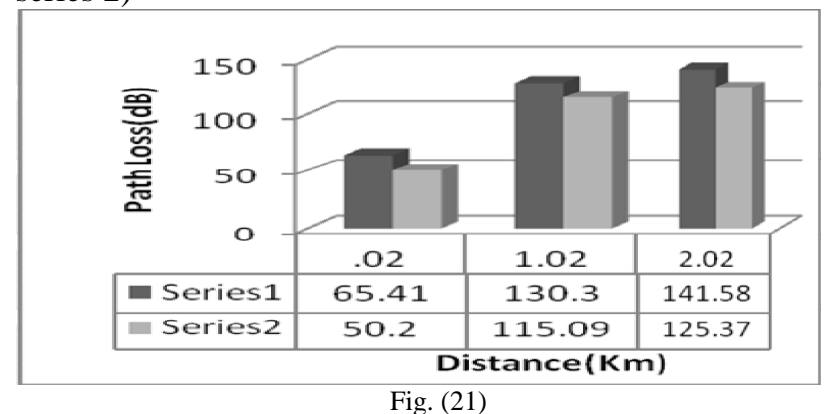

From the figure-21 it is clear that values of path loss goes on decreasing with increase in values of the base station.

\section{E. Egli Propagation Model}

The effect of increasing frequency, the base station antenna height and the height of mobile station antenna height on path loss equation of the Egli propagation model has been shown as below in the figures:-

Let us see first effect of base station antenna height:-

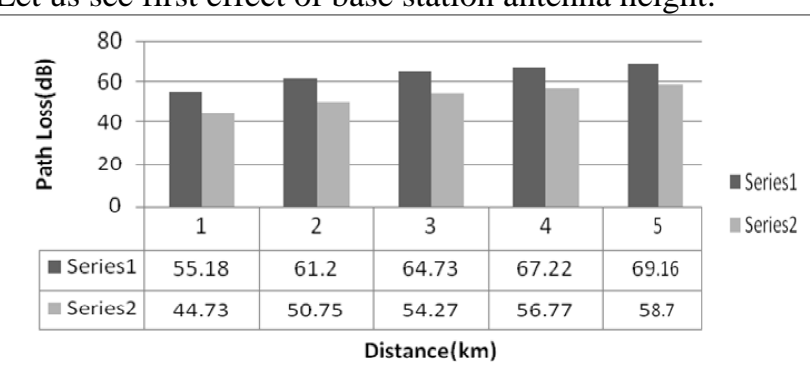

Fig.22 Analysis for increased base station height

By analysing the figure-22 it can be concluded that the path loss is more at hte $=30 \mathrm{~m}$, and it get decreased as the value hte is increased i.e at hte $=100 \mathrm{~m}$.

For series1:-

f $(\mathrm{MHz}) \quad \mathrm{d}(\mathrm{Km})$

hte $(\mathrm{m})$ 
150 $1-5$

30 1

For series2:-

f $(\mathrm{MHz})$

$\mathrm{d}(\mathrm{Km})$

$\mathrm{hr}(\mathrm{m})$

150

$1-5$

100

For series 1 the value of hte $=30$, and in series 2 it is $=100$ So we can see that as value of hte is increased the propagation loss is decreasing as shown in figure- 22 .

Now we will see the effect of change in receiver antenna height:-

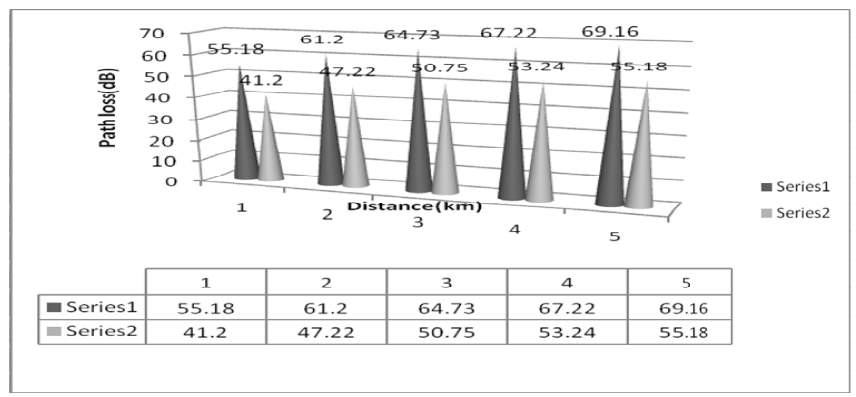

Fig.23 Analysis for increased receiver antenna height.

For series1:-

\begin{tabular}{|c|c|c|c|}
\hline \multirow{3}{*}{$\begin{array}{l}\mathrm{f}(\mathrm{MHz}) \\
\mathrm{hr}(\mathrm{m}) \\
150\end{array}$} & \multicolumn{2}{|c|}{$\mathrm{d}(\mathrm{Km})$} & hte(m) \\
\hline & & & \\
\hline & $1-5$ & 30 & 1 \\
\hline $\begin{array}{l}\text { For series 2:- } \\
\mathrm{f}(\mathrm{MHz})\end{array}$ & & & hte(m) \\
\hline 150 & $1-5$ & 30 & 5 \\
\hline
\end{tabular}

For series 2 when value of $\mathrm{hr}$ is increased to $5 \mathrm{~m}$ the propagation loss is getting slowdown as shown in the figure-23.

\section{F. Walfisch And Bertoni Model}

The graphical analysis of the model is given as below:-

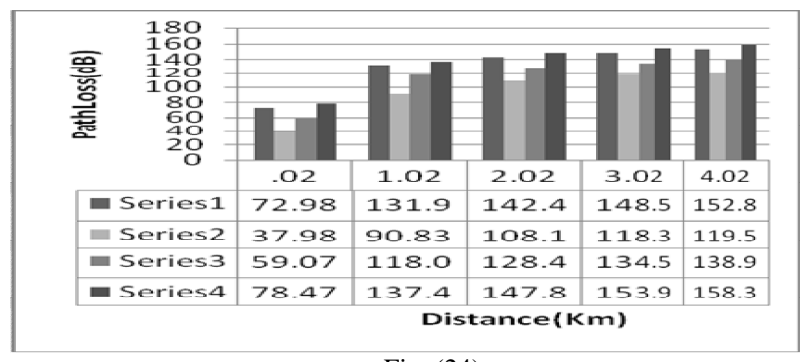

Fig. (24)

The value of frequency, base station antenna height, receiver antenna height and distance between transmitter and receiver for different series may be given as below:-

For series 1:-

$\begin{array}{lccc}\mathrm{f}(\mathrm{MHz}) & \mathrm{d}(\mathrm{m}) & \mathrm{hte}(\mathrm{m}) & \mathrm{hr}(\mathrm{m}) \\ 800 & 0.02-4.02 & 4 & 1\end{array}$

For series 1:-

$800 \quad 0.02-4.02 \quad 50 \quad 1$

For series 1:-

$800 \quad 0.02-4.02 \quad 4 \quad 5$

For series 1:-

$\begin{array}{lccc}\mathrm{f}(\mathrm{MHz}) & \mathrm{d}(\mathrm{m}) & \mathrm{hte}(\mathrm{m}) & \mathrm{hr}(\mathrm{m}) \\ 1200 & 0.02-4.02 & 4 & 1\end{array}$

By analysing the figure-24 it can be concluded that the path loss increases with the increase in distance and is more at hte $=4 \mathrm{~m}$, and it get decreased as the value hte is increased i.e at hte $=50 \mathrm{~m}$. For series 3 when value of $\mathrm{hr}$ is increased to $5 \mathrm{~m}$ the propagation loss is getting slowdown as shown in the diagram. In series 4 when frequency is increased to $1200 \mathrm{MHz}$ the loss also increases.

The figure-25 gives the graphical analysis of increase in receiver antenna height in walfisch and bertoni model:-

For series 1:-

$\mathrm{f}(\mathrm{MHz}) \quad \mathrm{d}(\mathrm{Km}) \quad$ hte $(\mathrm{m})$

$\mathrm{hr}(\mathrm{m})$

$800 \quad 0.02-5 \quad 4 \quad 1$

For series 2:-

$\mathrm{f}(\mathrm{MHz}) \quad \mathrm{d}(\mathrm{Km}) \quad$ hte $(\mathrm{m})$

$\operatorname{hr}(\mathrm{m})$

$\begin{array}{llll}800 & 0.02-5 & 4 & 5\end{array}$

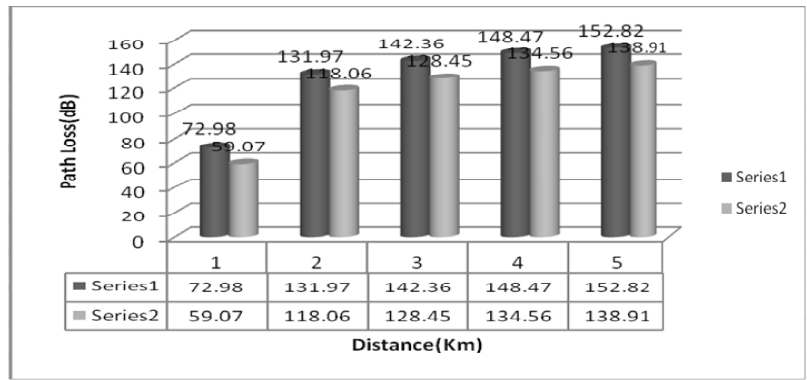

Fig.25 Analysis for changing value of receiving antenna

For series 2 when value of $\mathrm{hr}$ is increased to $5 \mathrm{~m}$ the propagation loss is getting slowdown as shown in the figure-25.

The following figure-26 shows the change in path loss when range of frequency is increased from $800 \mathrm{Mhz}$ to 1200 Mhz :-

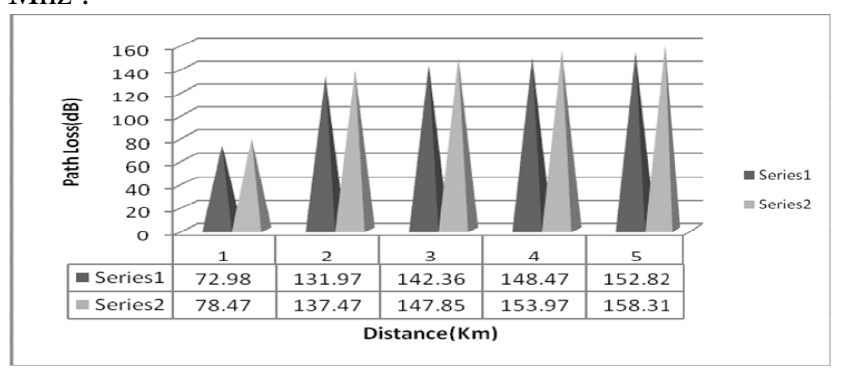

Fig.26 Analysis for increased frequency

For series 1:-

$\mathrm{f}(\mathrm{MHz}) \quad \mathrm{d}(\mathrm{Km}) \quad$ hte $(\mathrm{m})$ $\mathrm{hr}(\mathrm{m})$

$800 \quad 0.02-5 \quad 4 \quad 1$

For series 2:-

$\mathrm{f}(\mathrm{MHz}) \quad \mathrm{d}(\mathrm{Km}) \quad$ hte $(\mathrm{m})$

$\mathrm{hr}(\mathrm{m})$

$\begin{array}{llll}1200 & 0.02-5 & 4 & 1\end{array}$

From the graphical analysis of figure-26, it is clear that with increase in frequency the propagation loss increases in walfisch and bertoni model.

\section{EXPERIMENTAL RESULTS}

The computed results of various empirical propagation models after implementation of concept of CSP provide a set of parameters of frequency (f), receiver antenna height(hr), the range of cell $(\mathrm{d} / \mathrm{r})$ and base station antenna height $(\mathrm{hb})$ at 
which propagation loss was found minimum for each empirical models which were undertaken for study. The graphical analysis of propagation loss and its dependence on other parameters has been shown in the figures (b). From the figure it is clear that the path loss increases with the increase in distance $(\mathrm{d} / \mathrm{r})$, decreases with the the increase in base station height (hb) and receiver antenna (hr) and as the frequency goes on increasing the path loss also increases.

\section{CONCLUSION}

From the work reported herein, it gives a brief survey of basic solving techniques behind constraint programming. In particular we concentrate on constraint satisfaction algorithm that are use to solve the constraint satisfaction problem. In this paper the various wireless empirical propagation models has been solved to find the propagation loss using the constraint satisfaction algorithm. We also overview the main technique of solving constraint optimization problem. For this we make use the constraint satisfaction optimization algorithm and optimization algorithm has been implemented on the different empirical propagation models in order to find the parameters such as frequency (f), base station antenna height( $\mathrm{hb}$ ), receiver antenna height (hr), and distance between transmitter and receiver $(\mathrm{d} / \mathrm{r})$ at which minimum propagation loss occur.

After implementing the CSP algorithms on wireless empirical propagation models it may be concluded that that the propagation loss increases as the distance between transmitter and receiver increases, and it decreases with increase in height of base station, and it also increases with increase in frequency and decreases with the increase in height of mobile station.

The main idea was to find the more accurate parameters which gives the accurate and reliable propagation loss predictions.

\section{REFERENCES}

[1] Tope r. Karem,H. Anthony chan, "A Low cost design of next generation Sonet/Sdh network with multiple constraint", IEEE, National Research Foundation, 2007

[2] Stuart Bain, John Thorton, Abdul Sattar "Evolving Algorithm For Constraint Satisfaction”, IEEE, pp 265-272, 2004.

[3] Edward Tsang, "Foundation of constraints satisfaction", Department of computer science University of Essex Colchester Essex, UK

[4] Tiong Sieh Kiong, Zeti Akma, Loo Hooi KAR, poh Tzye Perng, "Propagation Loss models characterization for GSM 900MHz at Kaula Lumpur and putrajaya", College of Engineering, Universiti Tenaga Malaysia

[5] Theodore S. Rappaport, "Wireless Communication System: Principles and Practice”, Second Edition, Prentice Hall of India Private Limited, 2005.

[6] V.S Abhayawardhana, I.J Wassell, D. Crosby,M.P. Sellars,M.G. Brown "Comparison of Empirical propagation path Loss Models for Fixed Wireless Access Systems", BT Mobility Research Unit, U.K., University of Cambridge.

[7] Josip Milanovic, Snjezana Rimac-Drlje,Krunoslav Bejuk, "Comparison of propagation model Accuracy for Wi MAX on 3.5 GHz", IEEE,1-4244-1378-8/07, 2007

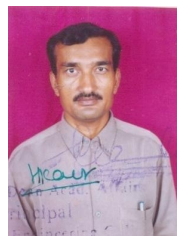

First Author: Prof. Nagendra Sah was born in Jaynagar, India, on 05-01-1960. He is Sr. Lecturer in PEC University of Technolgy ( Formerly PEC-Deemed University), Chandigarh, India. He has done his B.Tech degree in Electronics and Communication Engg. from Regional Engineering College ( Now National Institute of Technolgoy)
Warangal, Andhra Pradesh, India in 1986 and Master of Engg. Degree in Electronics Engg. From Panjab University, Chandigarh, India in 2005. He has teaching experience of about 18 years. Presntly, he is working as Sr. Lecturer. He has published about 22 papers in national and international conferences. His research is focused on the radio-system design, the investigation and modeling of mobile radio propagation and the development of simulation methodsfor a mobile radio channel.

Membership in Professional Societies: Member of IACSIT, SINGAPORE.

\section{ACSI TMemberNumber 80331337}

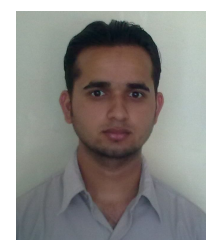

Second Author: Amit Kumar was born at Una, India on 11-03-1986. He is enrolled as student of Master Degree in Electronics Engg . in PEC- University of Technology, Chandigarh, India. He has done his B.E. Degree in Electronics and Communication Engg. from Green Hills College of Engineering, Solan, Himachal Pradesh, India in 2007 . 